\title{
Pulmonary rehabilitation in COPD - available resources and utilization in Swedish primary and secondary care
}

This article was published in the following Dove Press journal:

International Journal of COPD

8 June 2017

Number of times this article has been viewed

\author{
Josefin Sundh' \\ Helena Lindgren ${ }^{2}$ \\ Mikael Hasselgren ${ }^{2}$ \\ Scott Montgomery ${ }^{3-5}$ \\ Christer Janson ${ }^{6}$ \\ Björn Ställberg ${ }^{7}$ \\ Karin Lisspers ${ }^{7}$
}

'Department of Respiratory Medicine, School of Medical Sciences, ${ }^{2}$ Medical

Programme, School of Medical

Sciences, ${ }^{3}$ Clinical Epidemiology

and Biostatistics, School of Medical

Sciences, Örebro University,

Örebro, ${ }^{4}$ Clinical Epidemiology Unit,

Department of Medicine, Karolinska

Institutet, Stockholm, Sweden;

${ }^{5}$ Department of Epidemiology and

Public Health, University College,

London, UK; ${ }^{6}$ Department of Medical

Sciences, Respiratory, Allergy and

Sleep Research, ${ }^{7}$ Department of Public

Health and Caring Science, Family

Medicine and Preventive Medicine,

Uppsala University, Uppsala, Sweden
Introduction: Pulmonary rehabilitation is effective in all stages of COPD. The availability and utilization of pulmonary rehabilitation resources, and the characteristics of COPD patients receiving rehabilitation, were investigated in primary and secondary care in central Sweden.

Materials and methods: Data on available pulmonary rehabilitation resources were collected using questionnaires, to 14 hospitals and 54 primary health care centers, and information on utilization of different rehabilitation professionals was obtained from questionnaires completed by 1,329 COPD patients from the same centers. Multivariable logistic regression examined associations with having received rehabilitation in the previous year.

Results: In primary care, nurse-based asthma/COPD clinics were common (87\%), with additional separate access to other rehabilitation professionals. In secondary care, rehabilitation was more often offered as part of a multidisciplinary teamwork (71\%). In total, 36\% of the patients met an asthma/COPD nurse in the previous year. Utilization was lower in primary than in secondary care for physiotherapists ( $7 \%$ vs $16 \%$ ), occupational therapists ( $3 \%$ vs $10 \%$ ), nutritionists ( $5 \%$ vs $13 \%$ ), and counselors ( $1 \%$ vs $4 \%$ ). A higher COPD Assessment Test score and frequent exacerbations were associated with higher utilization of all rehabilitation professionals.

Conclusion: Pulmonary rehabilitation resources are available but underutilized, and receiving rehabilitation is more common in severe COPD. Treatment recommendations need to be better implemented, especially in mild and moderate COPD.

Keywords: multidisciplinary, asthma/COPD nurse, physiotherapist, occupational therapist, nutritionist, counselor

\section{Introduction}

Pulmonary rehabilitation is an important aspect of COPD management, for improvement of symptoms, physical activity, daily function, social activities, and knowledge of the disease in order to promote better self-management. ${ }^{1-4}$ It is recommended in patients with forced expiratory volume in one second $<80 \%$ of predicted value, although patients in all spirometry stages of disease could benefit from interventions like exercise training programs and smoking prevention. ${ }^{5}$ It is also successful for improvement of patient-related outcomes in all Global Initiative on Obstructive Lung Disease (GOLD) 2014 A-D groups ${ }^{6}$ and all modified Medical Research Council stages. ${ }^{7}$

Pulmonary rehabilitation is often based on a multidisciplinary approach, and can comprise physical training, energy-saving techniques, aid for activities of daily life, nutritional intervention, support from a counselor, and patient education for selfmanagement skills and smoking cessation. ${ }^{2,8}$ It is commonly provided using established rehabilitation programs, such as the British Thoracic Society Quality Standards for 
pulmonary rehabilitation programs that include 6 weeks with a minimum of twice-weekly supervised sessions, and a defined structured education program. ${ }^{9}$

An important characteristic of pulmonary rehabilitation in Sweden is that there are not always fixed rehabilitation programs, but instead it is common to have separate directed interventions by different rehabilitation professionals. The use of directed interventions means that the same quality standards could be achieved, although more customized. The most common professionals involved in pulmonary rehabilitation in Sweden, besides physicians, are asthma/ COPD nurses, physiotherapists, occupational therapists, nutritionists, and counselors/psychologists. Interventions by these professionals can be performed at hospitals as well as in primary health care centers (PHCCs). The majority of Swedish patients with COPD are managed at PHCCs, although they can be referred to secondary care by the general practitioner if a complete rehabilitation program is needed. Also, COPD patients discharged from hospital for a COPD exacerbation are often referred to asthma/COPD nurses at PHCCs for follow-up including rehabilitation interventions. According to the Swedish national guidelines, all stable COPD patients should be recommended physical training and structured education about the disease, and if needed nutritional intervention and aid for activities of daily life. ${ }^{10,11}$ Physical training could include both individual training programs and group training. COPD group training is commonly offered by physiotherapists at Swedish hospitals, but the corresponding physical training can often be performed at PHCCs as well.

Several studies have investigated access to pulmonary rehabilitation programs. ${ }^{12-15}$ However, very few have explored the availability of specific rehabilitation professionals, ${ }^{12,15,16}$ and few, if any, studies have compared pulmonary rehabilitation in primary and secondary care. ${ }^{14}$ The aim of this study was to investigate the availability and use of pulmonary rehabilitation resources in COPD, and what characterizes COPD patients participating in multidisciplinary pulmonary rehabilitation, in a multicenter study of primary and secondary care in central Sweden.

\section{Materials and methods Data collection}

In 2005, the first COPD cohort within the PRAXIS study was created, a research project with data collection from patients in primary and secondary care in seven county councils in central Sweden. ${ }^{17-22}$ Each county council was represented by the department of respiratory medicine in its central hospital, the department of internal medicine from one randomly selected district hospital, and eight randomly selected PHCCs. All data used in this study were collected using questionnaires, to the caregivers and to the patients. In 2012, a questionnaire about available resources for asthma and COPD care was completed by the original participating centers, 14 hospitals and 54 out of 56 PHCCs. A second cohort was randomly selected in 2014, from lists of all patients aged 18-74 with doctor's diagnoses of COPD (ICD-10 code J44) during the period of 2007-2010 at each center. A questionnaire was sent to 2,310 COPD patients and completed by 1,329 COPD patients (Figure 1). Approximately two-thirds of the patients were obtained from PHCCs, reflecting the fact that the majority of the patients with COPD in Sweden are managed in primary care.

\section{Patient characteristics and resources at participating centers}

The questionnaires about resources included questions of whether the centers had an asthma/COPD nurse, a

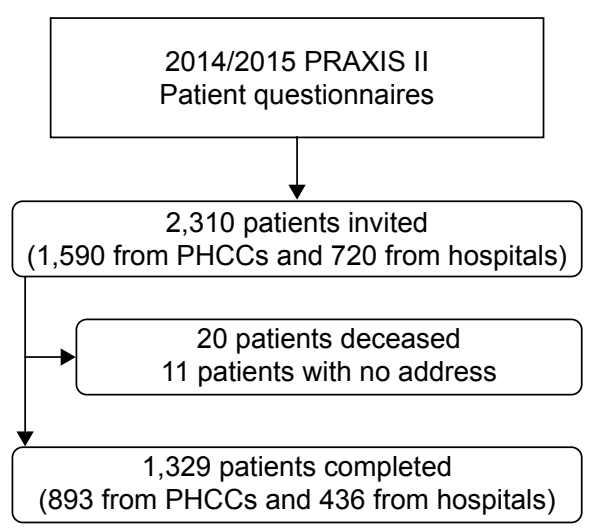

Figure I Flowchart.

Abbreviation: PHCCs, primary health care centers. 
physiotherapist for asthma/COPD patients, an occupational therapist, a nutritionist, and a counselor or psychologist. There was also a question if multidisciplinary teamwork was applied, as in established pulmonary rehabilitation programs, and if the center had a nurse-based asthma/COPD clinic. In Sweden, nurse-based asthma/COPD clinics are often used as an important part of COPD management. An asthma/ COPD clinic, which is integrated into PHCC or hospital, should include a nurse with special education in respiratory diseases and tobacco prevention, a responsible physician, and scheduled time for structured investigations, management, and education of patients.

The patient questionnaires provided information on age, sex, smoking habits, level of education, physical activity, height, weight, number of exacerbations in the previous year, a doctor's diagnosis of heart disease, depression, or diabetes, and appointments with rehabilitation professionals in the previous year. Health status was assessed using the COPD Assessment Test (CAT). ${ }^{23}$ Age was categorized as $<61,61-70$, and $>70$ years. Smoking habits were categorized as never smoking, ex-smoking, occasional smoking, and current daily smoking; and the logistic regression variable included current daily smoking or not. The dichotomous educational variable identified the most highly educated group as those who had continued in full-time education for at least 2 years beyond the Swedish compulsory school period of 9 years. Self-assessed physical activity was reported in four categories: 1 , no physical activity; 2, walking or bicycling at least 4 hours/week; 3 , exercise training at least 3 hours/week; or 4 , advanced and regular exercise training several times a week. Body mass index (BMI) in $\mathrm{kg} / \mathrm{m}^{2}$ was calculated from self-estimated length and weight and categorized as underweight (BMI $<20)$, normal weight (BMI 20-24), overweight (BMI 25-29), and obesity (BMI $\geq 30$ ). Exacerbations were defined as emergency visits to primary or secondary care during the previous year due to deterioration in lung disease, and were grouped as 0,1 , or $\geq 2$. The CAT score was dichotomized as low health status or not (CAT score $\geq 10$ vs $<10$ according to GOLD). ${ }^{5}$

\section{Statistics}

Analyses were performed using SPSS version 22.0 (IBM Corporation, Armonk, NY, USA). Cross-tabulation and $\chi^{2}$ test investigated patient characteristics, available resources, and appointments with rehabilitation professionals during the previous year, by level of care. Separate logistic regression analyses with having met the respective rehabilitation professionals in the previous year as dependent variables were performed. Independent variables included sex, age, current smoking, level of education, BMI, number of exacerbations recent year, heart disease, diabetes, and depression/ anxiety (categorical variables), and physical activity and CAT (continuous variables). Multivariate analysis included sex, age, and measures statistically significantly associated with one or several professionals in the univariate analysis, in the population with complete data on all included variables $(n=1,156)$. Stratification and multiplicative interaction analysis was used to assess effect modification by sex and level of care (primary or secondary) for the associations of the independent variables with the rehabilitation outcomes. A $P$-value of $<0.05$ was considered statistically significant.

\section{Ethical considerations}

The study was approved by the Regional Ethical Review Board in Uppsala (Dnr 2010/090). Written informed consent was given by all the patients and health care professionals.

\section{Results}

\section{Patient characteristics}

The distributions of patient characteristics by level of care are presented in Table 1. In summary, a higher proportion of patients in secondary care had heart disease, low physical activity, exacerbations in the previous year, and poor health status and were not current smokers.

\section{Available pulmonary rehabilitation resources}

Presence of asthma/COPD clinics and multidisciplinary teamwork in pulmonary rehabilitation, by level of care, is presented in Table 2. The proportions of available separate professionals in primary care outside the context of a specified multidisciplinary teamwork are presented in Table 3. In summary, there was high access to asthma/COPD clinics in both levels of care although more common in primary care, and a comprehensive multidisciplinary teamwork including several professions was more common in secondary care.

When a multidisciplinary teamwork approach was used, physiotherapists were the most common professionals in both primary and secondary care. However, in primary care, counselors were the most common separate professionals outside the context of a specified multidisciplinary rehabilitation teamwork (Table 3).

\section{Utilization of pulmonary rehabilitation resources}

Figure 2 shows the proportions of COPD patients who had met the respective rehabilitation professionals in the 
Table I Patient characteristics

\begin{tabular}{|c|c|c|c|}
\hline $\begin{array}{l}\text { Patient } \\
\text { characteristics }\end{array}$ & $\frac{\text { Primary care }}{(\mathbf{N}=\mathbf{8 9 3})}$ & $\frac{\text { Secondary care }}{(\mathbf{N}=436)}$ & $P$-value \\
\hline \multicolumn{4}{|l|}{ Sex } \\
\hline Female & $496(56 \%)$ & $249(57 \%)$ & Ref \\
\hline Male & 397 (44\%) & 187 (43\%) & 0.589 \\
\hline \multicolumn{4}{|l|}{ Age (years) } \\
\hline$<61$ & I38 (I5\%) & $63(14 \%)$ & Ref \\
\hline $61-70$ & $4 I I(46 \%)$ & $212(49 \%)$ & 0.483 \\
\hline$>70$ & 344 (39\%) & |6I (37\%) & 0.890 \\
\hline \multicolumn{4}{|l|}{ Smoking } \\
\hline Never & $40(5 \%)$ & 17 (4\%) & 0.181 \\
\hline Ex & $516(59 \%)$ & $313(74 \%)$ & $<0.0001$ \\
\hline Occasionally & $54(6 \%)$ & $21(5 \%)$ & 0.243 \\
\hline Current daily & $270(31 \%)$ & $75(18 \%)$ & Ref \\
\hline \multicolumn{4}{|l|}{ Education } \\
\hline Low & $688(79 \%)$ & 342 (80\%) & Ref \\
\hline High & $182(21 \%)$ & $87(20 \%)$ & 0.789 \\
\hline \multicolumn{4}{|l|}{ Physical activity } \\
\hline I & $265(31 \%)$ & 172 (4I\%) & Ref \\
\hline 2 & $541(63 \%)$ & 227 (55\%) & 0.001 \\
\hline 3 & $49(5 \%)$ & $14(3 \%)$ & 0.010 \\
\hline 4 & $4(1 \%)$ & $2(1 \%)$ & 0.851 \\
\hline \multicolumn{4}{|l|}{ BMI } \\
\hline Underweight & $48(5 \%)$ & $34(8 \%)$ & 0.078 \\
\hline Normal & $217(25 \%)$ & $98(23 \%)$ & Ref \\
\hline Overweight & $354(41 \%)$ & $168(40 \%)$ & 0.747 \\
\hline Obesity & $250(29 \%)$ & 120 (29\%) & $0.7 I I$ \\
\hline \multicolumn{4}{|l|}{ Heart disease } \\
\hline No & $710(81 \%)$ & $317(74 \%)$ & Ref \\
\hline Yes & 168 (19\%) & II4 (26\%) & 0.002 \\
\hline \multicolumn{4}{|l|}{ Diabetes } \\
\hline No & 749 (85\%) & $356(82 \%)$ & Ref \\
\hline Yes & $129(15 \%)$ & $76(18 \%)$ & 0.174 \\
\hline \multicolumn{4}{|c|}{ Anxiety/depression } \\
\hline No & $669(76 \%)$ & $317(73 \%)$ & Ref \\
\hline Yes & $209(24 \%)$ & I 14 (27\%) & 0.297 \\
\hline \multicolumn{4}{|c|}{ Exacerbations recent year } \\
\hline 0 & $653(74 \%)$ & $255(60 \%)$ & Ref \\
\hline I & $120(14 \%)$ & $77(18 \%)$ & 0.002 \\
\hline$\geq 2$ & $104(12 \%)$ & $92(22 \%)$ & $<0.0001$ \\
\hline \multicolumn{4}{|l|}{ Health status } \\
\hline $\mathrm{CAT}<\mathrm{IO}$ & $220(26 \%)$ & $80(20 \%)$ & Ref \\
\hline $\mathrm{CAT} \geq 10$ & $628(74 \%)$ & $331(80 \%)$ & 0.011 \\
\hline
\end{tabular}

Notes: Patient characteristics, distributed over level of care. In variables with two categories, $\chi^{2}$ test was used. In variables with $>2$ categories, univariable logistic regression was used to compare each category with the reference category. Physical activity categories: I, no physical activity; 2, walking or bicycling at least 4 hours/ week; 3, exercise training at least 3 hours/week; or 4, advanced and regular exercise training several times a week.

Abbreviations: BMI, body mass index; CAT, COPD Assessment Test; Ref, reference group.

Table 2 Access to asthma/COPD clinics and multidisciplinary team work

\begin{tabular}{llll}
\hline Rehabilitation resources & PHCCs & & Hospitals \\
& $\mathbf{( n = 5 4 )}$ & & $\mathbf{( n = 1 4 )}$ \\
\hline Asthma/COPD clinics & $47(87 \%)$ & & $10(71 \%)$ \\
Multidisciplinary teamwork & $21 / 54(39 \%)$ & & $10 / 14(71 \%)$ \\
Physiotherapist & $20 / 21(95 \%)$ & & $10 / 10(100 \%)$ \\
Occupational therapist & $13 / 21(62 \%)$ & & $8 / 10(57 \%)$ \\
Nutritionist & $7 / 21(33 \%)$ & & $9 / 10(64 \%)$ \\
Counselor or psychologist & $10 / 21(48 \%)$ & $9 / 10(64 \%)$ \\
\hline
\end{tabular}

Note: Access to asthma/COPD clinics and rehabilitation professionals within a multidisciplinary teamwork, distributed over level of care.

Abbreviation: PHCCs, primary health care centers.
Table 3 Access to separate professions in PHCCs

\begin{tabular}{ll}
\hline Rehabilitation professionals in primary care & N (\%) \\
\hline Asthma/COPD nurse with special education & $44 / 54(82 \%)$ \\
Physiotherapist & $44 / 54(82 \%)$ \\
Occupational therapist & $38 / 54(70 \%)$ \\
Nutritionist & $33 / 54(61 \%)$ \\
Counselor or psychologist & $53 / 54(98 \%)$
\end{tabular}

Note: Access to separate rehabilitation professionals in primary care.

Abbreviation: PHCCs, primary health care centers.

previous year. The asthma/COPD nurses were involved in approximately a third of the patients. The remaining professionals were significantly more often utilized in secondary care although overall in much lower numbers.

\section{Characteristics of patients who received rehabilitation}

In the multivariable logistic regression, two or more exacerbations in the previous year were statistically significantly associated with having met all rehabilitation professionals. Lower health status was associated with having met all rehabilitation professionals except a counselor. Male sex, underweight, and diabetes were associated with having met a nutritionist, and depression/anxiety was associated with having seen a counselor. Current smoking was associated with not having met a nurse, a physiotherapist or a counselor, and overweight and obesity were both associated with not having seen a physiotherapist or a nutritionist (Table 4; Figure 3).

The stratification and interaction analysis by sex showed a statistically significant association for current smoking with not having seen a nutritionist in women (odds ratio [OR] [95\% confidence interval $\{\mathrm{CI}\}], 0.22[0.07$ to 0.69$]$ ) but not in men (1.01 [0.44 to 2.33], $P$-value for interaction 0.046$)$ and for depression/anxiety with having seen a counselor in men (OR [95\% CI], 18.6 [1.65 to 210.8]) but not in women (1.24 [0.41 to 3.74], $P$-value for interaction 0.018 ). The stratification and interaction analysis by level of care showed no statistically significant differences (data not shown).

\section{Discussion}

The first main finding of our study is that access to rehabilitation resources in Sweden is rather good, but that the main problem seems to be underutilization of available rehabilitation professionals. The second main finding is that patients receiving rehabilitation are predominantly those with more severe disease as assessed by exacerbation frequency and health status. 


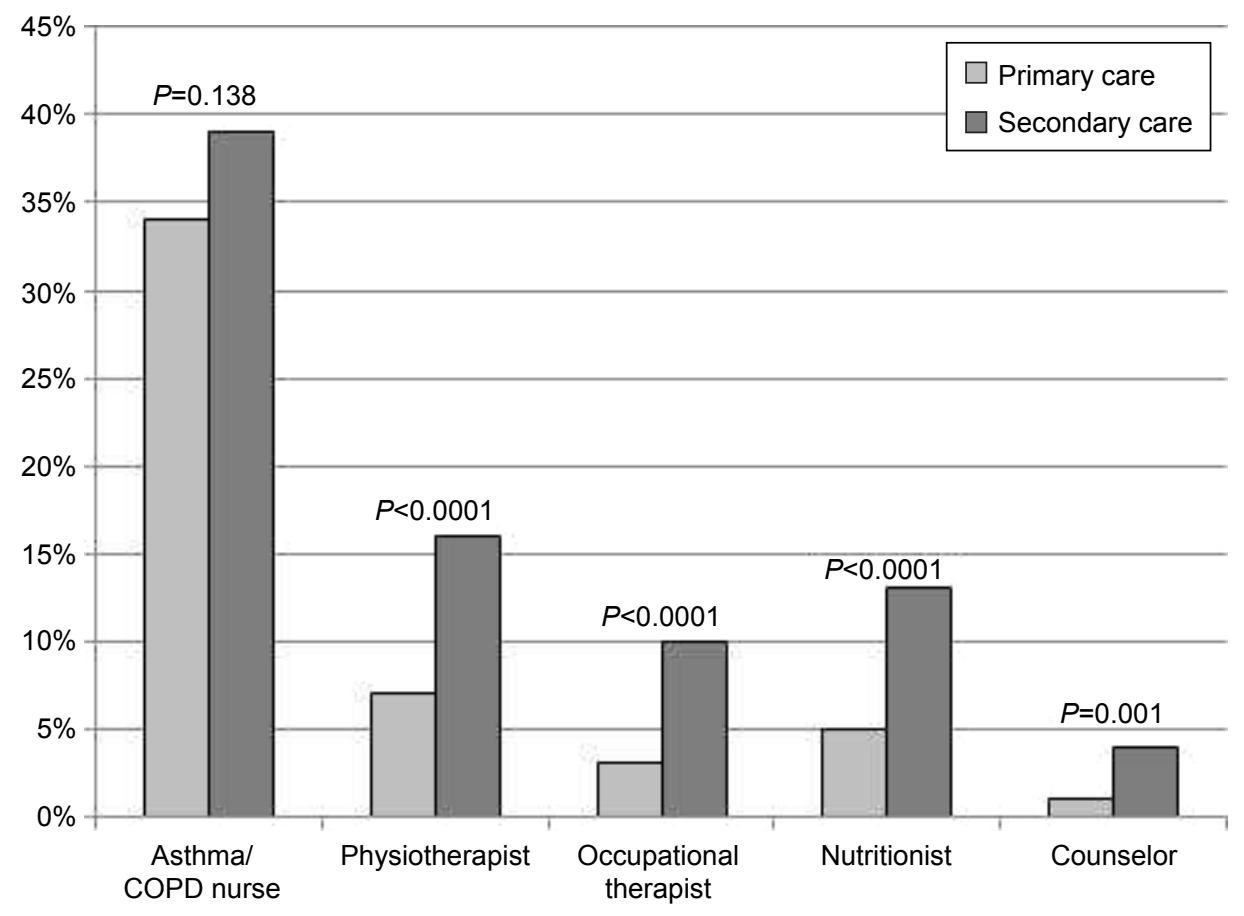

Figure 2 Utilization of rehabilitation professionals in the previous year.

Note: Proportions of patients having met pulmonary rehabilitation professionals in the previous year, distributed over level of care.

\section{Available pulmonary rehabilitation resources}

The questionnaires about resources show that nurse-based asthma/COPD clinics are common in primary care, and have increased from two-thirds of PHCCs, as found in the first PRAXIS study in 2005 , to $87 \%$ in $2012 .{ }^{24}$ In contrast, asthma/COPD clinics are less common in secondary care but secondary care centers are using multidisciplinary teamwork to a greater extent. Interestingly, although the use of a comprehensive multidisciplinary teamwork in rehabilitation is less common in primary care, the availability of separate rehabilitation professionals is much higher. The results of the resource questionnaires mirror the fact that primary and secondary COPD care are organized in different ways, which is reasonable as the characteristics of patients differ by level of care. In primary care, many aspects of rehabilitation such as education and counseling are performed by the asthma/ COPD nurse, while rehabilitation in hospitals more often includes several professionals.

The findings of available pulmonary rehabilitation in $71 \%$ of hospitals are consistent with a previous Swedish study where Wadell et al found that $66 \%$ of all Swedish hospitals offered pulmonary rehabilitation programs, ${ }^{12}$ and with a recent study of Swedish primary care where Arne et al found that $49 \%$ of all participating PHCCs offered pulmonary rehabilitation for COPD patients. ${ }^{16}$ However, this study expands the investigation to include both availability and utilization of pulmonary rehabilitation in primary as well as secondary COPD care. In comparison, a UK study in 2004 showed that only $40 \%$ of the surveyed hospitals had rehabilitation programs $\mathrm{s}^{13}$ and a Canadian study published in 2015 reported that $67 \%$ of the investigated centers, mainly hospitals, offered complete pulmonary rehabilitation. ${ }^{14}$ A comprehensive report of the content and organization of pulmonary rehabilitation programs in 430 centers mainly in Europe and the USA has been published by the European Respiratory Society (ERS) COPD Audit, showing huge differences in settings and participating rehabilitation professionals. ${ }^{15}$ Overall the access to physiotherapists, nurses, and nutritionists was most common, $\sim 60 \%-70 \%$, which is consistent with the results of this study. The paper from the ERS COPD Audit was based on a survey directed to representatives of pulmonary rehabilitation programs and associations. As discussed, there was probably selection bias where suggested reasons for not responding were language problems, a heavy work load, and not being aware of the survey. An additional potential reason may be that part of pulmonary rehabilitation is offered outside the concept of fixed programs, due to lack of resources or clear organization.

The importance of rehabilitation interventions is welldocumented. Exercise training increases quality of life, 
Table 4 Patient characteristics associated with having seen different rehabilitation professionals in the previous year

\begin{tabular}{|c|c|c|c|c|c|}
\hline $\begin{array}{l}\text { Patient } \\
\text { characteristics }\end{array}$ & $\begin{array}{l}\text { Asthma/COPD nurse } \\
\text { OR }(95 \% \mathrm{Cl})\end{array}$ & $\begin{array}{l}\text { Physiotherapist } \\
\text { OR }(95 \% \mathrm{Cl})\end{array}$ & $\begin{array}{l}\text { Occupational therapist } \\
\text { OR }(95 \% \mathrm{Cl})\end{array}$ & $\begin{array}{l}\text { Nutritionist } \\
\text { OR }(95 \% \mathrm{Cl})\end{array}$ & $\begin{array}{l}\text { Counselor } \\
\text { OR }(95 \% \mathrm{Cl})\end{array}$ \\
\hline Male sex & $\mathrm{I} .00(0.78$ to $\mathrm{I} .30)$ & $0.8 \mathrm{I}(0.5 \mathrm{I}$ to I.27) & $1.20(0.64$ to 2.26$)$ & $\mathrm{I} .70$ (I.03 to 2.82$)$ & $0.60(0.22$ to 1.65$)$ \\
\hline \multicolumn{6}{|l|}{ Age (years) } \\
\hline$<61$ & Ref & Ref & Ref & Ref & Ref \\
\hline $6 I-70$ & $\mathrm{I} .35(0.9 \mathrm{I}$ to I.98) & $1.39(0.70$ to 2.78$)$ & 0.83 (0.34 to 2.01$)$ & 1.97 (0.84 to 4.62$)$ & $0.5 \mathrm{I}$ (0.15 to I.68) \\
\hline$>70$ & I. .28 (0.85 to I.92) & 1.32 (0.64 to 2.73 ) & $0.82(0.32$ to 2.13$)$ & I.7I (0.69 to 4.20$)$ & 0.58 (0.16 to 2.03$)$ \\
\hline Current smoking & $0.70(0.5 \mathrm{I}$ to 0.95$)$ & 0.31 (0.17 to 0.55$)$ & $0.46(0.20$ to I.06) & 0.54 (0.28 to I.02) & $0.09(0.01$ to 0.73$)$ \\
\hline Physical activity & 1.05 (0.83 to I.32) & $0.96(0.64$ to I.44) & $0.62(0.33$ to I.I5) & I.I8 (0.74 to I.86) & 0.7 I (0.28 to I.78) \\
\hline \multicolumn{6}{|l|}{ BMI } \\
\hline Underweight & 0.55 (0.30 to I.0I) & I.19 (0.55 to 2.59$)$ & $\mathrm{I} .83(0.69$ to 4.86$)$ & 2.98 (1.35 to 6.56$)$ & $3.53(0.8 \mid$ to I5.3) \\
\hline Normal & Ref & Ref & Ref & Ref & Ref \\
\hline Overweight & $\mathrm{I} .06(0.77$ to I.47) & 0.49 (0.26 to 0.78$)$ & $0.75(0.34$ to I.66) & $0.50(0.26$ to 0.96$)$ & 1.05 (0.27 to 4.14$)$ \\
\hline Obesity & 0.98 (0.69 to I.40) & 0.43 (0.23 to 0.79$)$ & $0.46(0.19$ to 1.15$)$ & 0.44 (0.22 to 0.89$)$ & 1.04 (0.26 to 4.19$)$ \\
\hline Diabetes & $\mathrm{I} .07$ (0.75 to I.53) & 1.27 (0.69 to 2.32$)$ & 1.35 (0.58 to 3.18$)$ & 4.02 (2.24 to 7.22$)$ & 1.65 (0.48 to 5.63$)$ \\
\hline Anxiety/depression & $\mathrm{I} .03(0.76$ to I.40) & $\mathrm{I} .33(0.8 \mathrm{I}$ to 2.17$)$ & 1.23 (0.62 to 2.42$)$ & $\mathrm{I} .58(0.9 \mathrm{I}$ to 2.74$)$ & 2.56 (I.03 to $6.4 I)$ \\
\hline \multicolumn{6}{|l|}{ Exacerbations } \\
\hline 0 & Ref & Ref & Ref & Ref & Ref \\
\hline 1 & 1.33 (0.94 to I.89) & 1.89 (I.04 to 3.43$)$ & 3.65 (1.60 to 8.36$)$ & $1.29(0.63$ to 2.65$)$ & 5.07 ( 1.15 to 22.4$)$ \\
\hline$\geq 2$ & 2.04 (I.40 to 2.96$)$ & 5.35 (3.16 to 9.05$)$ & 5.54 (2.54 to I I 2.1$)$ & 3.65 (2.04 to 6.55$)$ & $11.3(2.91$ to 43.6$)$ \\
\hline Health status (CAT) & 1.06 (I.04 to I.07) & 1.06 (I.03 to I.09) & 1.08 (I.04 to I.I3) & I.08 (I.04 to I.II) & $1.07(1.00$ to 1.15$)$ \\
\hline
\end{tabular}

Note: Results from multivariable logistic regression analyses with separate pulmonary rehabilitation professionals as dependent variables and sex, age, and statistically significant variables from the univariable analyses as independent variables.

Abbreviations: BMI, body mass index; CAT, COPD Assessment Test; $\mathrm{Cl}$, confidence interval; OR, odds ratio; Ref, reference group.

diminishes dyspnea, and increases physical capacity in COPD GOLD 2011 stage II-IV, ${ }^{25}$ and improves dyspnea, fatigue, and physical capacity in COPD GOLD 2011 stage I-III. ${ }^{26}$ Especially important is exercise training following a COPD exacerbation, where organized training also decreases hospitalization and mortality. ${ }^{26}$ Energysaving techniques have a documented effect on functional capacity and ability to perform activities in daily life. ${ }^{27}$ In patients with $\mathrm{BMI}<22$, nutritional treatment is associated with increased physical capacity and quality of life, and decreased exacerbations and mortality. ${ }^{28}$ This study showed that physiotherapists were highly available in both primary and secondary care. The low access to occupational therapists in primary care could partly be explained by the fact that this profession sometimes belongs to the municipality organization and not to the health organization with county councils where this study was performed. Nevertheless, occupational therapists are underutilized. A complete multidisciplinary rehabilitation with several professionals, as recommended by national ${ }^{11}$ as well as international ${ }^{5}$ guidelines, is still warranted. The fact that the availability of pulmonary rehabilitation is not optimal (but still acceptable), may be due to inadequate priorities in the health care system and due to lack of educated health care personnel.

\section{Utilization of pulmonary rehabilitation resources}

A low proportion of patients had actually met any of the various rehabilitation professionals in the previous year. Previous studies have mainly investigated resources, ${ }^{12-14,16}$ and the identification of underutilization is very important. The finding is consistent with an Italian study of COPD management where general practitioners stated that $13 \%$ of patients were referred to pulmonary rehabilitation in $^{29}$ and with a Swiss study of patients referred to hospitals due to exacerbation, where $27 \%$ had participated in pulmonary rehabilitation. ${ }^{30}$ Suggested reasons for barriers to rehabilitation are lack of awareness of pulmonary rehabilitation in both patients and health care professionals, low access, low perceived health benefits, and comorbidity. ${ }^{31}$ A review of factors preventing people from attending rehabilitation raises the problem of transport to rehabilitation..$^{32}$ This issue was also raised in the earlier referred study by Wadell et al. ${ }^{12}$ However, as the patients with mild disease were those with least received rehabilitation in this study, it is believed that the physicians' reluctance to refer to pulmonary rehabilitation may be of greater importance here.

The logistic regression analyses showed that patients receiving rehabilitation had more severe disease as assessed 

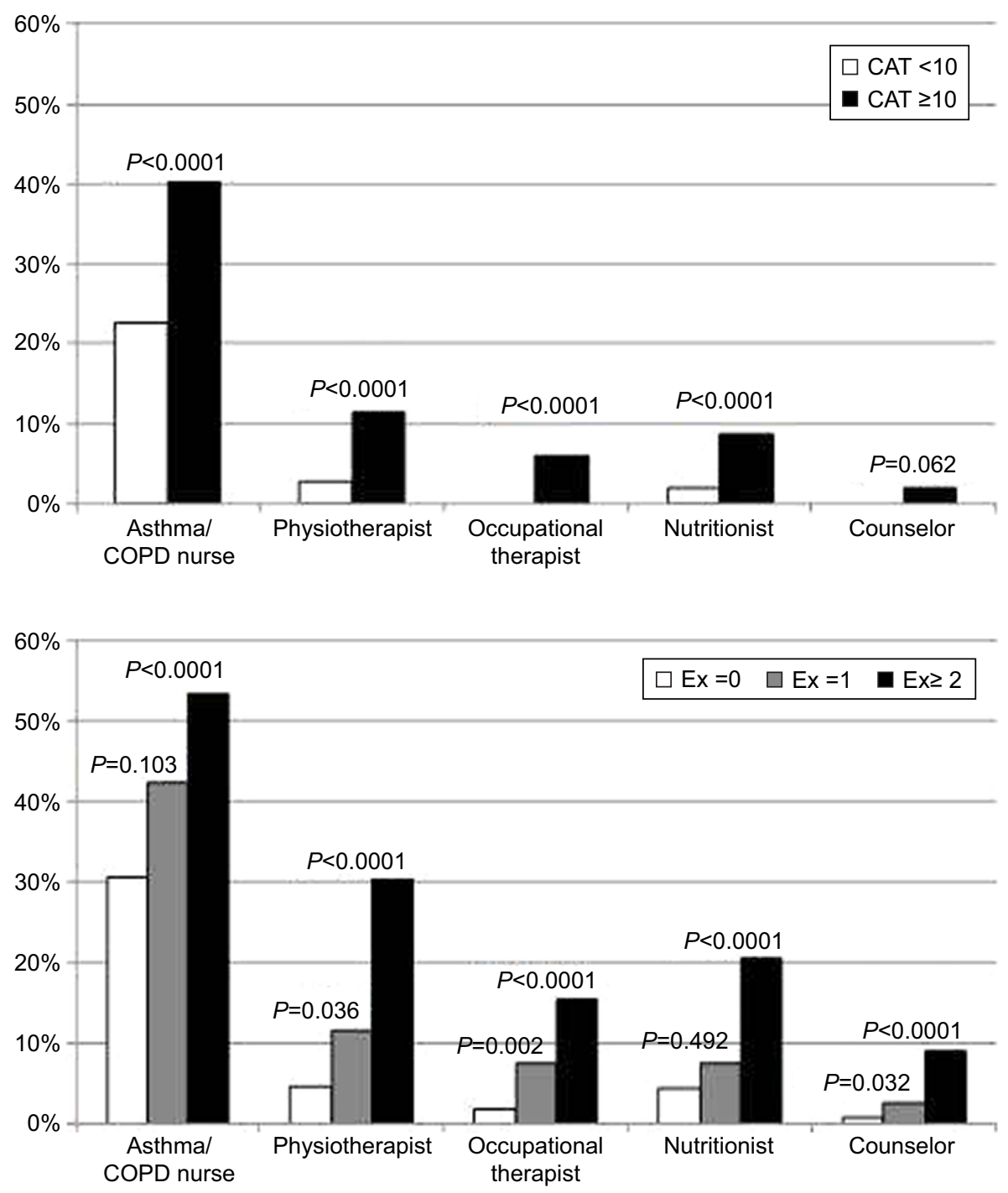

Figure 3 Patient factors associated with having received multidisciplinary rehabilitation.

Notes: Proportions of patients with stable and low health status and respective annual number of exacerbations having met different pulmonary rehabilitation professionals in the previous year. $P$-values from multivariable regression analyses.

Abbreviations: CAT, COPD Assessment Test; Ex, numbers of COPD exacerbations recent year.

by health status and exacerbation frequency, established predictors of mortality in COPD patients. ${ }^{33,34}$ This probably also explains why contact with rehabilitation professionals was more common in secondary care, where patients with more severe COPD were managed. However, pulmonary rehabilitation is of benefit also in mild disease and is recommended by GOLD to be implemented in all stages of COPD. ${ }^{5}$ In our opinion, it is very important to apply particularly physical training and advice from a physiotherapist in the early stages of the disease, in order to maintain the level of physical capacity and health status.

The fact that current smoking was associated with not having seen several of the rehabilitation professionals recent year may be partly explained by a "healthy smoker effect" where patients with preserved lung function do not consider smoking cessation as necessary. ${ }^{35}$ However, since the association remains after adjusting for severity markers such as health status and exacerbations, the finding also indicates a subgroup of patients with little interest in health care contacts and interventions. Analogously, overweight and obese patients were less likely to visit a physiotherapist and a nutritionist. In contrast, being underweight and having diabetes were both associated with having seen a nutritionist, in accordance with the guidelines. ${ }^{5}$ Interestingly, male sex was associated with having seen a nutritionist. This could be consistent with the previous finding that overweight is associated with better health-related quality of life in men but not in women with $\mathrm{COPD},{ }^{17}$ and that men therefore to 
a greater extent might accept the idea of gaining weight if $\mathrm{BMI}$ is $<22$. As for the remaining associations of utilization of pulmonary rehabilitation with sex, age, and education level, no significant differences were shown. This is an encouraging fact, indicating that Swedish COPD care is equal in these aspects.

Stratification and interaction by sex showed that smoking women are less likely to see a nutritionist than smoking men, and depression/anxiety is a more important factor for seeing a counselor in men than in women, possibly suggesting more severe disease in men.

\section{Strengths and limitations}

The strength of this study is that it is a multicenter realworld study with patients from both primary and secondary care, which together with a fairly high response rate to questionnaires ensures a high level of external validity and generalizability.

An important potential limitation is that the inclusion criterion of the patient population is a doctor's diagnosis of COPD. In this study, only patient questionnaires were used, and the COPD diagnoses were not confirmed by record review of spirometry, which means that the patient population could possibly include patients with an incorrect COPD diagnosis. ${ }^{36}$ The possibility that some of the patients received rehabilitation earlier than in the previous year cannot be excluded but, as the effect of rehabilitation is known to last for up to a year, the utilization frequency is still too low. ${ }^{8}$

\section{Clinical implications}

Smoking cessation, pharmacotherapy, and pulmonary rehabilitation are all major cornerstones in the treatment of COPD. Pulmonary rehabilitation denotes a broad spectrum of interventions, where patients with severe disease may need more advanced support from several rehabilitation professionals. In these cases, national agreements often recommend that patients are referred to hospitals for complete rehabilitation programs. However, the concept of pulmonary rehabilitation is not restricted to patients with severe disease. On the contrary, directed interventions such as physiotherapist contact for supplying exercise programs and structured education by an asthma/COPD nurse for increased selfmanagement are also examples of pulmonary rehabilitation. These interventions may well be used in primary as well as in secondary care, in any stage of the disease, in order to decrease symptoms and to prevent progression of the disease. An important clinical implication of this study is that rehabilitation professionals are available separately, rather than as part of comprehensive rehabilitation programs, and that they are underutilized. It is speculated that the underutilization is mainly due to lack of awareness of the importance of pulmonary rehabilitation, which emphasizes the need of implementation of the recently updated national recommendations for COPD care. ${ }^{10,11}$

The results, interpretations, and suggested implications of this study are consistent with the recent American Thoracic Society/ERS policy statement of pulmonary rehabilitation, which among other things emphasizes the need of developing new models for pulmonary rehabilitation to increase the access and the inclusion of patients with mild and moderate airflow limitation. In addition, the need of pragmatic "real world" trials and studies of barriers and facilitators of pulmonary rehabilitation is stated. ${ }^{37}$

\section{Conclusion}

It is concluded that many COPD patients did not meet the rehabilitation professionals in the previous year, which is partly due to insufficient resources but mainly due to underutilization of COPD rehabilitation. The present guidelines and treatment recommendations need to be better implemented, especially among patients with mild and moderate disease.

\section{Acknowledgments}

The study was supported by the county councils of the Uppsala-Örebro Health Care region, the Swedish Heart and Lung Association, the Swedish Asthma and Allergy Association, the Bror Hjerpstedts Foundation, the Örebro Society of Medicine and the Region Örebro County through funding by ALF (Avtal om Läkarutbildning och Forskning [Agreement concerning Cooperation on Medical Education and Research]). This paper is original and the abstract of the paper was presented at the Swedish Respiratory Society Congress in Örebro on April 21, 2016 as an oral presentation, and at the European Respiratory Society Congress in London on September 7, 2016 as a thematic poster. The poster's abstract was published in the European Respiratory Journal September 2016, volume 48, supplement 60.

\section{Disclosure}

The authors report no conflicts of interest in this work.

\section{References}

1. Spruit MA, Singh SJ, Garvey C, et al. An official American Thoracic Society/European Respiratory Society statement: key concepts and advances in pulmonary rehabilitation. Am J Respir Crit Care Med. 2013; 188(8):e13-e64.

2. Troosters T, Casaburi R, Gosselink R, Decramer M. Pulmonary rehabilitation in chronic obstructive pulmonary disease. Am J Respir Crit Care Med. 2005;172(1):19-38. 
3. McCarthy B, Casey D, Devane D, Murphy K, Murphy E, Lacasse Y. Pulmonary rehabilitation for chronic obstructive pulmonary disease. Cochrane Database Syst Rev. 2015;2:CD003793.

4. Puhan MA, Gimeno-Santos E, Cates CJ, Troosters T. Pulmonary rehabilitation following exacerbations of chronic obstructive pulmonary disease. Cochrane Database Syst Rev. 2016;12:CD005305.

5. Global Initiative for Chronic Obstructive Lung Disease. Global Strategy for the Diagnosis, Management, and Prevention of Chronic Obstructive Pulmonary Disease. Available from: http://www.goldcopd. com. Accessed February 18, 2017.

6. Alfarroba S, Rodrigues F, Papoila AL, Santos AF, Morais L. Pulmonary rehabilitation in COPD according to global initiative for chronic obstructive lung disease categories. Respir Care. 2016;61(10):1331-1340.

7. Evans RA, Singh SJ, Collier R, Williams JE, Morgan MD. Pulmonary rehabilitation is successful for COPD irrespective of MRC dyspnoea grade. Respir Med. 2009;103(7):1070-1075.

8. Chavannes NH, Grijsen M, van den Akker M, et al. Integrated disease management improves one-year quality of life in primary care COPD patients: a controlled clinical trial. Prim Care Respir J. 2009; 18(3):171-176.

9. Bolton CE, Bevan-Smith EF, Blakey JD, et al. British Thoracic Society guideline on pulmonary rehabilitation in adults. Thorax. 2013; 68 (Suppl 2):ii1-ii30.

10. The Swedish Medical Product Agency. Läkemedelsbehandling av kroniskt obstruktiv lungsjukdom (KOL). 2015 [updated October 16, 2015; cited February 18, 2017]. Available from: https://lakemedelsverket.se/ upload/halso-och-sjukvard/behandlingsrekommendationer/Kroniskt_ obstruktiv_lungsjukdom_KOL_behandlingsrekommendation.pdf. Accessed February 18, 2017.

11. The Swedish National Board of Health and Welfare. Vård vid astma och KOL. 2015 [updated November 3, 2015; cited February 18, 2017] Available from: http://www.socialstyrelsen.se/Lists/Artikelkatalog/ Attachments/19949/2015-11-3.pdf. Accessed February 18, 2017.

12. Wadell K, Janaudis Ferreira T, Arne M, Lisspers K, Ställberg B, Emtner M. Hospital-based pulmonary rehabilitation in patients with COPD in Sweden - a national survey. Respir Med. 2013;107(8):1195-1200.

13. Yohannes AM, Connolly MJ. Pulmonary rehabilitation programmes in the UK: a national representative survey. Clin Rehabil. 2004;18(4): 444-449.

14. Bowen JM, Campbell K, Sutherland S, et al. Pulmonary rehabilitation in Ontario: a cross-sectional survey. Ont Health Technol Assess Ser. 2015; 15(8):1-67.

15. Spruit MA, Pitta F, Garvey C, et al. Differences in content and organisational aspects of pulmonary rehabilitation programmes. Eur Respir J. 2014;43(5):1326-1337.

16. Arne M, Emtner M, Lisspers K, Wadell K, Ställberg B. Availability of pulmonary rehabilitation in primary care for patients with COPD: a cross-sectional study in Sweden. Eur Clin Respir J. 2016;3:31601.

17. Sundh J, Ställberg B, Lisspers K, Montgomery SM, Janson C. Comorbidity, body mass index and quality of life in COPD using the Clinical COPD Questionnaire. COPD. 2011;8(3):173-181.

18. Sundh J, Janson C, Lisspers K, Ställberg B, Montgomery S. The Dyspnoea, Obstruction, Smoking, Exacerbation (DOSE) index is predictive of mortality in COPD. Prim Care Respir J. 2012;21(3):295-301.

19. Sundh J, Janson C, Lisspers K, Montgomery S, Ställberg B. Clinical COPD Questionnaire score (CCQ) and mortality. Int J Chron Obstruct Pulmon Dis. 2012;7:833-842.

20. Sundh J, Osterlund Efraimsson E, Janson C, Montgomery S, Ställberg B, Lisspers K. Management of COPD exacerbations in primary care: a clinical cohort study. Prim Care Respir J. 2013;22(4):393-399.
21. Sundh J, Ställberg B, Lisspers K, Kampe M, Janson C, Montgomery S Comparison of the COPD Assessment Test (CAT) and the Clinical COPD Questionnaire (CCQ) in a clinical population. COPD. 2016;13(1):57-65.

22. Sundh J, Montgomery S, Hasselgren M, et al. Change in health status in COPD: a seven-year follow-up cohort study. NPJ Prim Care Respir Med. 2016;26:16073.

23. Jones PW, Harding G, Berry P, Wiklund I, Chen WH, Kline Leidy N. Development and first validation of the COPD Assessment Test. Eur Respir J. 2009;34(3):648-654.

24. Lisspers K, Ställberg B, Janson C. Omhändertagande av patienter med kroniskt obstruktiv lungsjukdom (KOL) i Uppsala-Örebroregionen. 2007 [updated September 1, 2016; cited February 18, 2017]. Available from: http://praxisstudien.se/texter/KOL-rapport\%202007.pdf. Accessed February 18, 2017.

25. Garcia-Aymerich J, Lange P, Benet M, Schnohr P, Anto JM. Regular physical activity reduces hospital admission and mortality in chronic obstructive pulmonary disease: a population based cohort study. Thorax. 2006;61(9):772-778.

26. Berry MJ, Rejeski WJ, Adair NE, Zaccaro D. Exercise rehabilitation and chronic obstructive pulmonary disease stage. Am J Respir Crit Care Med. 1999;160(4):1248-1253.

27. Lorenzi CM, Cilione C, Rizzardi R, et al. Occupational therapy and pulmonary rehabilitation of disabled COPD patients. Respiration. 2004;71(3):246-251.

28. Ferreira IM, Brooks D, White J, Goldstein R. Nutritional supplementation for stable chronic obstructive pulmonary disease. Cochrane Database Syst Rev. 2012;12:CD000998.

29. Maio S, Baldacci S, Martini F, et al. COPD management according to old and new GOLD guidelines: an observational study with Italian general practitioners. Curr Med Res Opin. 2014;30(6):1033-1042.

30. Fritsch K, Jacot ML, Klarer A, et al. Adherence to the Swiss guidelines for management of COPD: experience of a Swiss teaching hospital. Swiss Med Wkly. 2005;135(7-8):116-121.

31. Johnston K, Grimmer-Somers K, Young M, Antic R, Frith P. Which chronic obstructive pulmonary disease care recommendations have low implementation and why? A pilot study. BMC Res Notes. 2012; $5: 652$.

32. Keating A, Lee A, Holland AE. What prevents people with chronic obstructive pulmonary disease from attending pulmonary rehabilitation? A systematic review. Chron Respir Dis. 2011;8(2):89-99.

33. Casanova C, Marin JM, Martinez-Gonzalez C, et al. Differential effect of modified Medical Research Council dyspnea, COPD Assessment Test, and Clinical COPD Questionnaire for symptoms evaluation within the new GOLD staging and mortality in COPD. Chest. 2015; 148(1):159-168.

34. Soler-Cataluna JJ, Martinez-Garcia MA, Roman Sanchez P, Salcedo E, Navarro M, Ochando R. Severe acute exacerbations and mortality in patients with chronic obstructive pulmonary disease. Thorax. 2005;60(11):925-931.

35. Jimenez-Ruiz CA, Masa F, Miravitlles M, et al. Smoking characteristics: differences in attitudes and dependence between healthy smokers and smokers with COPD. Chest. 2001;119(5):1365-1370.

36. Arne M, Lisspers K, Ställberg B, et al. How often is diagnosis of COPD confirmed with spirometry? Respir Med. 2010;104(4):550-556.

37. Rochester CL, Vogiatzis I, Holland AE, et al. An official American Thoracic Society/European Respiratory Society policy statement: enhancing implementation, use, and delivery of pulmonary rehabilitation. Am J Respir Crit Care Med. 2015;192(11):1373-1386. 


\section{Publish your work in this journal}

The International Journal of COPD is an international, peer-reviewed This journal is indexed on PubMed Central, MedLine and CAS. The journal of therapeutics and pharmacology focusing on concise rapid reporting of clinical studies and reviews in COPD. Special focus is given to the pathophysiological processes underlying the disease, intervention programs, patient focused education, and self management protocols. manuscript management system is completely online and includes a very quick and fair peer-review system, which is all easy to use. Visit http://www.dovepress.com/testimonials.php to read real quotes from published authors. 